\title{
Guidelines
}

\section{Patient and Patient Group Engagement in Cancer Clinical Trials: A Stakeholder Charter}

\author{
Stéphanie Michaud ${ }^{1}$ (D), Judy Needham ${ }^{2}$, Stephen Sundquist ${ }^{3}$, Dominique Johnson ${ }^{4}$, Sabrina Hanna ${ }^{5}$, \\ Sharareh Hosseinzadeh ${ }^{6}$, Vatche Bartekian ${ }^{7}$ (D), Patricia Steele ${ }^{8}$, Sarita Benchimol ${ }^{8}$, Nathalie Ross ${ }^{9}$ \\ and Barry D. Stein ${ }^{8, *}$
}

check for updates

Citation: Michaud, S.; Needham, J.; Sundquist, S.; Johnson, D.; Hanna, S.; Hosseinzadeh, S.; Bartekian, V.; Steele, P.; Benchimol, S.; Ross, N.; et al. Patient and Patient Group Engagement in Cancer Clinical Trials: A Stakeholder Charter. Curr. Oncol. 2021, 28, 1447-1458. https://doi.org/ 10.3390 /curroncol28020137

Received: 26 January 2021

Accepted: 2 April 2021

Published: 8 April 2021

Publisher's Note: MDPI stays neutral with regard to jurisdictional claims in published maps and institutional affiliations.

Copyright: (c) 2021 by the authors. Licensee MDPI, Basel, Switzerland. This article is an open access article distributed under the terms and conditions of the Creative Commons Attribution (CC BY) license (https:// creativecommons.org/licenses/by/ $4.0 /)$.
1 BioCanRx, Ottawa, ON K1H 8L6, Canada; smichaud@biocanrx.com

2 Canadian Cancer Trials Group, Kingston, ON K7L 3N6, Canada; judy.needham@telus.net

3 Canadian Cancer Clinical Trials Network (3CTN), Toronto, ON M5G 0A3, Canada; Stephen.Sundquist@oicr.on.ca

4 McPeak-Sirois Group for Clinical Research in Breast Cancer, Montreal, QC H2Y 2H2, Canada; d.johnson@mcpeaksirois.org

5 The Cancer Collaborative, Montreal, QC H7W 0C3, Canada; sabrina@cancercolab.ca

6 Novartis Pharma Canada, Dorval, QC H9S 1A9, Canada; sharareh.hosseinzadeh@novartis.com

Vantage BioTrials, Montreal, QC H4M 2N9, Canada; vatche@vantagebiotrials.com

8 Colorectal Cancer Canada, Montreal, QC H3G 1J1, Canada; patricias@colorectalcancercanada.com (P.S.); saritab@colorectalcancercanada.com (S.B.)

9 Nathalie Ross, Laval, QC H7L 4Z3, Canada; info@nathalieross.com

* Correspondence: barrys@colorectalcancercanada.com

\begin{abstract}
Background-to guide the implementation of patient centricity and engagement in cancer clinical trials (CTs) and to operationalize the Canadianized version of the Clinical Trials Transformation Initiative (C-CTTI) model, the development of a charter was identified by cancer CT stakeholders. Methods-the Canadian Cancer Trial Stakeholder Charter (the Charter) was initiated by Colorectal Cancer Canada (CCC) and developed via the-1-formation of an inclusive working group (WG) that drafted the document using recommendations collected during the development of the C-CTTI model; 2-socialization of the draft Charter to solicit feedback from cancer CT stakeholders, including those who attended the 2019 CCC Conference; and 3-incorporation of stakeholders' feedback and finalization of the Charter by the WG. Results-the Charter was built around five guiding principles-1-patient centricity; 2-commitment to education and training; 3-collaboration as equal and independent partners in research; 4-transparency and accountability; and 5-high standards in data collection integrity and honesty. These principles led to the Charter's five tenets, which stipulate stakeholder commitments, aiming to make CTs accessible to all patients, improve the design and implementation of CTs to benefit patients, expand recruitment and retention of patients in CTs, and further advance cancer research and treatment. Conclusions-the Charter is intended to integrate the patient voice into the Canadian cancer CT continuum. The next phases of the C-CTTI model include the adoption and implementation of the Charter, the establishment of a patient group training program, and the development of real-world evidence/real-world data methodologies.
\end{abstract}

Keywords: cancer patient groups; Canadian Cancer Clinical Trials; patient centricity; patient engagement; Clinical Trials Transformation Initiative; stakeholder charter; real-world evidence; realworld data

\section{Introduction}

Establishing partnerships with patients and patient groups (PGs) to engage them in all levels of clinical trials (CTs), including in real-world evidence research, is increasingly explored and applied globally [1-23]. Keys to such engagement-also referred to as codesign research, participatory research, patient-oriented research (POR), patient-involved 
research, patient public involvement, patient participation, co-creative research, citizen science, patient-centric initiative, open science-are the understanding and the manifestation of the concept of patient centricity or patient centeredness [1,3,4,24-27].

Advantages of involving the end-user groups in the broad research agenda include increased research relevance to both clinicians and patients [1], with positive impacts reported in setting research priorities, developing proposals, recruiting and retaining patients, as well as disseminating results, including societal and ethical benefits $[2,4,7,9,10$, 14,28-33]. Guidelines and recommendations are emerging on research partnerships with patients, which support the principles of trust, respect, and co-learning $[2,7,13,18,19,22,34]$. These include POR training for all team members, tools/resources for successful patient engagement, and value for patient partnerships across various stages of the research cycle.

Co-founded by the US Food and Drug Administration and Duke University, and incepted in 2007 as a model for multi-stakeholder engagement in CTs, the Clinical Trials Transformation Initiative (CTTI) led to a significant commitment to help grow and shape patient engagement $[18,35]$. CTTI defines CT stakeholders as not only the potential participants to enroll in the study, but also the other individuals whose time and effort are needed to develop and execute the project [36]. CT stakeholders can be grouped under-participants (e.g., patients and families), PGs (e.g., support groups and advocacy groups), providers and clinicians (e.g., investigators and community providers), community (e.g., culture and gender), trial management staff (e.g., data management and statistician), site staff (e.g., principal investigators and study coordinators), allied health staff (e.g., nursing and pharmacy), and others (e.g., regulatory authorities, funders, and contract-research organizations). The CTTI recommendations [37] for specific actions and considerations to improve the design and execution of CTs have become a roadmap for patient engagement strategic planning.

Examples of patient engagement initiatives in Canada include recommendations from a panel of expert Canadian emergency medicine researchers on best practices for the engagement of patients in emergency medicine (EM), with the aim to improve EM research by helping researchers select meaningful outcomes, increase social acceptability of studies, and design knowledge translation strategies that target patients' needs [19]. Focusing on 12 Canadian teams engaged in community-based primary health research, Kendall et al. [38] reported on the engagement of patients and other stakeholders in different stages of research, frequency and length of engagement, as well as facilitators of engagement. Challenges were identified around communication, time, and finding the appropriate stakeholder to engage with.

Specifically in cancer CTs in Canada, initiatives to engage patients include the Getting better Outcomes with Chimeric Antigen Receptor T-cell therapy (GO-CART) program, which showed that engaging patients in early phase trials helped in each component of the study, including the development of the study protocol, non-technical summary, interview and survey questions, as well as estimating costs for the early economic analysis [4].

Despite developments on patient and PG engagement in health research, including the well-known frameworks of Patient-Centered Outcomes Research Institute (PCORI) in the US, INVOLVE in the UK, and Strategy for Patient-Oriented Research (SPOR) in Canada $[3,4,6,23,38-40]$, in practice the prevalence of patient engagement across CTs remains extremely low; less than $1 \%$ as reported by Fergusson et al. [15] in a systematic review from May 2011 to June 2016. An unmet need resides in providing tangible tools for CT stakeholders to commit to the principle of patient centricity and patient engagement $[5,41,42]$ as well as empowering patients to fulfil their role specifically in cancer CTs.

Initiated by Colorectal Cancer Canada (CCC) [43] following a consensus meeting in June 2017 on Patient Group Pathway Model to Accessing Cancer CTs, an expert working group (WG) developed a Canadianized version of the CTTI model (C-CTTI), presented in detail in Batist et al. [44] (Figure 1). The C-CTTI takes into account specificities of the Canadian CT environment related to the effects of global decision-making and systems of regulatory and funding approvals. 


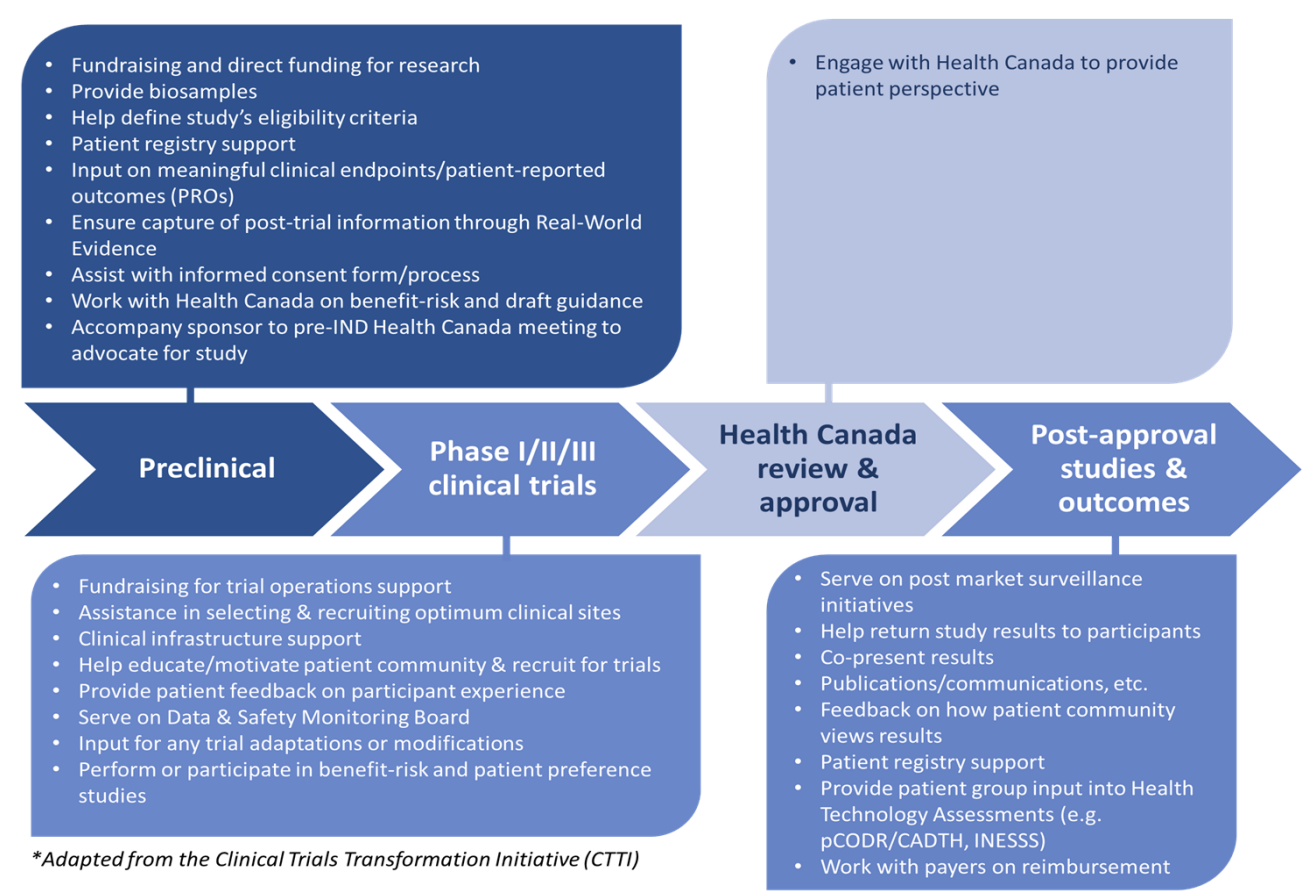

Figure 1. Canadianized Clinical Trials Transformation Initiative (C-CTTI)—a model of a PG pathway for engagement in cancer clinical trials (CTs) in Canada.

As a step to operationalize the C-CTTI model, the CCC and WG were mandated in 2018 to develop a charter that would provide a framework for cancer CTs to help guide the relationships among all stakeholders, empower PGs and patients, make CTs accessible to all patients, improve the design and implementation of CTs to benefit patients, improve recruitment and retention of patients in CTs, and further advance cancer research and treatment. Presented herein are the charter development process, the five tenets that are the pillars to the charter, and the related stakeholders' commitments.

\section{Materials and Methods}

\subsection{Step 1: Drafting the Charter}

Following an endorsement of the C-CTTI model [44] in June 2017 as a model to guide patient integration into all phases of cancer research and development in Canada, the participants of the 2018 Patient Group Pathway Model to Accessing Cancer Clinical Trials and Real-World Evidence Conference mandated CCC and the WG (Table S1) to develop a charter document.

Aiming at facilitating the acceptance of PG representatives participating as equal partners in CTs, the WG, composed of scientists/clinicians, individuals from PGs and advocacy groups, cooperative academic CT oncology groups, representatives from health agencies, research networks/consortium, industry partners, contract research organizations (CROs), as well as key participants from CCC, drafted the Canadian Cancer Trial Stakeholder Charter (the Charter). The draft Charter encompassed recommendations collected from the WG consensus meetings (December 2017 and April 2018) during the development of the C-CTTI model (Figure 2). The draft Charter development process included a series of WG sessions, leading to an initial draft considered and revised to integrate feedback, and an updated version made available for a socializing phase in time for the 2019 CCC conference. 


\section{Recommandations for all stakeholders}

1. Engage the "patient voice" by establishing partnerships starting at the preclinical phase of the research and development program to improve trial design and execution.

2. From the start, clearly define the expectations, roles and responsibilities of all partners, e.g., patient groups, including the resources being committed, data being shared and objectives of the program.

3. Build the trust required for successful partnerships by being transparent and trustworthy, following through on commitments, and honouring confidentiality.

4. Involve the expertise of multiple partners for a broader perspective to mitigate risk and enrich pipeline development.

5. Manage real or perceived conflicts of interest by establishing policies that require full disclosure, transparency, and accountability.

\section{Recommendations for research sponsors - industry and academia}

1.Integrate into your ongoing research and portfolio planning an assessment of patient group expertise, assets and value to your program

2. Match patient group expertise and assets to the specific needs and phases of your research and development programs.

3.Ensure that patient groups are essential partners throughout the research and development process and not token voices.

4.For consistency, establish guiding principles and clear lines of communication to facilitate a fit-forpurpose process for collaborating with patient groups.

5.Measure the impact of patient group engagement.

6.Establish ongoing relationships with patient groups and communicate openly with them on a regular basis.

\section{Recommendations for patient groups}

1. Proactively identify, engage and bring the patients' voices to stakeholders relevant to your clinical research interests.

2.Promote your value as an essential partner by maximizing and articulating your expertise and assets.

3.Deliver expertise and assets to sponsors throughout the entire research and development process.

4.Select sponsors who have a product or program with significant promise for your constituents and who are committed to engaging in a meaningful way.

5.Manage real or perceived conflicts of interest by establishing policies that require full disclosure, transparency and accountability.

Figure 2. Recommendations from stakeholders of the 2017 Colorectal Cancer Canada (CCC) conference for integrating PGs in cancer CTs, used in the drafting process of the Charter.

\subsection{Step 2: Socializing the Charter}

In 2018-2019, the draft Charter was circulated to various stakeholders including PGs and trial sponsors, and feedback was incorporated into the different Charter versions. An important source of feedback came from the CCC Patient Group Pathway Model to Accessing Cancer Clinical Trials and Real-World Evidence Methodologies Conference, held in Montreal, Quebec on 16-17 October 2019. During this conference, feedback was collected via a Sprint session [45] using an agile methodology [46] —an iterative approach divided in a series of sub-group discussions and re-group sharing sessions-maximizing the quality and quantity of feedback provided.

The scope of this Sprint session was two-fold-to create awareness for, and educate on, the (new and draft) Charter and to gain stakeholders' input and feedback with the goal of incorporating this feedback into a final draft of the Charter. The Sprint Backlog, defined as the items to be completed during the Sprint session, were the following five questions: 
- How will PGs and patients benefit from this Charter?

- What specific feedback would you like to provide related to wording or information not to be missed?

- What ideas can you provide for successful implementation of this Charter?

- What should the roles and responsibilities of the PG be? and

- What hurdles do you anticipate in the implementation process? What ideas might you have for overcoming these hurdles?

The consolidated feedback from these sub-group discussions and re-group sharing sessions was identified as the minimal viable products (MVPs) from the Sprint session.

\subsection{Step 3: Finalizing the Charter}

The Charter WG reunited after the 2019 CCC meeting to integrate feedback received from the varied stakeholders, specifically to adjust wording for clarity and completeness. The main considerations for finalizing the Charter included-clarifying the intended target of the Charter, identifying a process to create awareness and promote acceptance and trust, developing implementation metrics and measures, as well as addressing privacy considerations. Through a series of wordsmithing iterations, and including the addition of a glossary, the Charter was finalized [47].

\section{Results}

\subsection{Consolidated Feedback from Stakeholders}

Started from ground zero and inspired by the "Novartis' Commitment to Patients and Caregivers" [48], the Charter, initiated by CCC, was developed by a dedicated WG through a rigorous process involving relevant stakeholders, including scientists/clinicians, individuals from PGs and advocacy groups, cooperative academic CT oncology groups, representatives from health agencies, research networks/consortium, industry partners, contract research organizations (CROs), as well as key participants from CCC. As a key contribution to the development of the Charter, stakeholders attending the CCC Patient Group Pathway Model to Accessing Cancer Clinical Trials and Real-World Evidence Methodologies Conference (Table S2) provided feedback, consolidated as minimal viable products (MVPs) in Figure 3, which was taken into consideration to finalize the Charter.

\subsection{The Canadian Cancer Trials Stakeholder Charter}

Adopters of the Charter believe that stakeholders must all strive for excellence when conducting cancer research and development as well as direct their efforts toward the development of treatments that provide clinically meaningful results with improved quality of life and patient outcomes.

The Charter-entitled the Canadian Cancer Trials Stakeholder Charter-was built around five guiding principles-1—patient centricity; 2 - commitment to education and training; 3-collaboration as equal and independent partners in research; 4-transparency and accountability; and 5-high standards in data collection integrity and honesty [47].

Aiming to make CTs accessible to all cancer patients, improve the design and implementation of CTs, expend recruitment and retention of patients in CTs, and further advance cancer research and treatment, and empower patients and PGs to fulfil their role, the adopters commit to the Charter's five tenets described below. A Charter's glossary is provided in Table S3. 


\section{How will patient groups and patients benefit from this Charter?}

- The concept of patient centricity must include PGs (and caregivers) in every steps of CTs, with the opportunity to provide tangible input, i.e., not just observers but equal independent partners.

- Education and training provided to PGs will be empowering, it will lead to unmet need to be identified and patient-centric outcomes to be developed.

- CTs recruitment and adherence will be improved, they will respond better to patient needs and their chance of success will be augmented.

\section{What specific feedback would you like to provide related to}

\section{wording or information not to be missed?}

- The concept of best practice in relation to patient centricity should be made an aspirational goal more than a fundamental goal.

- Consider emphasizing the engagement with patients and PGs early and frequently in the CT development process.

- The concepts of equal and independent partners to be well defined.

- 'We' to be defined, e.g., Adopters of the Charter.

- Make sure that transparency means presenting results when they are positive and negative.

- The concept of RWE/RWD to be well defined.

\section{What ideas can you provide for a successful implementation of this Charter?}

- Global decisions, made outside of the Canadian healthcare system, may bring both barriers and opportunities.

- Some opportunities include: higher quality of CTs, better recruitment, pool of educated patients, patient certification programs, patient empowerment, sociodemographic advantage for patients.

- Awareness to be created throughout various stakeholders and guidelines needed within the industry to create more engagement.

- A gap analysis to be conducted to develop a CT repository.

- Charter to be socialized at conferences to obtain wide buy-in by stakeholders.

\section{What should the roles and responsibilities of the patient group be?}

-Several roles and responsibilities were proposed for PGs:

- To communicate the availability of CTs, the importance of participating in a CT, and presenting outcomes of CTs to patients and caregivers

- To be part of the research proposal process and design, at an early stage, bringing patients' needs/perspective to researchers, validating the value to patients, and ensuring transparency and accountability

- To train/educate patients and caregivers to prepare them to fully participate in the research

- To support data collection, especially related to RWE/RWD

- PGs to become advocates, i.e., to promote and disseminate the Charter

What hurdles do you anticipate in the implementation process?

What ideas might you have for overcoming these hurdles?

- Hurdles to implementation may include: patient engagement in global CTs as well as confidential information, gaps of availability of CTs across the country, lack of research on outcomes related to patient centricity, scarcity of patient pools for rare diseases,

- Potential ways to improve across implementation were identified as: PGs to train patients, compensation for patients and caregivers, promote advocacy efforts at international conferences, use of plain/lay language to assist in knowledge transfer, clarify how the RWE will be used, encourage Sponsors to adopt the Charter

Figure 3. Summary of the feedback collected during the socialization of the draft Canadian Cancer Clinical Trials Stakeholder Charter, including the MVPs from the 2018 CCC conference. CCC: Colorectal Cancer Canada; CT, clinical trial; MVP: minimum viable product; PG, patient group; RWD, real-world data; RWE, real-world evidence. 


\subsubsection{Tenet 1: Making Patient Centricity a Norm in Clinical Trials}

What it means:

Using our best efforts to understand and integrate the patient perspective throughout the CT continuum by considering their experiences and needs. Patient input will be considered throughout the entire CT continuum.

Commitment to:

- Ensure that studies are designed to realize outcomes that are relevant to patients and includes their preferences and trade-offs, achieve clinically meaningful results and enhance patient quality of life and health outcomes, while minimizing the burden of disease and treatment on patients;

- Increase access to CTs by reducing barriers and ensuring that eligibility criteria are fair and appropriate;

- Simplify the informed consent document to provide transparent, comprehensible CT information in a language that is relevant for patients;

- Engage patients in a two-way communication throughout the CT continuum (CTC), solicit and incorporate their feedback, and provide access to mechanisms, such as digital and mobile health technologies where possible;

- Connect patients to internal and external support programs and other resources through convenient and user-friendly channels; and

- $\quad$ Provide patients with uninterrupted access to CT therapies.

3.2.2. Tenet 2: Supporting Education, Training and Development of Patient Group Members for Effective Participation in the Design and Implementation of Clinical Trial Protocols on Behalf of Patients

What it means:

Engaging PGs as equal partners, consistent with all other stakeholders, throughout the CT continuum and therefore recognizing their expertise, input, and experience are unique and valued.

Commitment to:

Engage with patients and PGs early on as well as on an ongoing basis to work together effectively throughout the CTC.

- Support training of PGs and evaluation initiatives while working collaboratively with them, encouraging their input and active participation in the development, implementation and reporting of a CT;

- Support PGs' ability to record patient values and preferences both during and post CT;

- Support training of other research Stakeholders including the Sponsor representatives, to ensure best practices are met in their engagement with PGs; and

- Evaluate and share the impact of our engagement with PGs.

3.2.3. Tenet 3: Collaborating with Patient Groups as Equal and Independent Partners to Optimize the Success of Clinical Trials

What it means:

Striving to change the culture of CTs to ensure that PGs are recognized as equal, independent partners to optimize the success of the trial.

Commitment to:

- Build strong partnerships with PGs and all Stakeholders by agreeing on joint expectations, responsibilities, and the commitment to promote co-operation;

- Include patient insight in the development of the consent process and patientfacing materials;

- Facilitate the connection between trial participants and PGs;

- Promote awareness and education of CTs among PGs, while integrating their involvement in the design and implementation of CTs;

- Work with PGs to integrate patient needs from the conception of CTs, to expedite and facilitate access to $\mathrm{CT}$ information, patient-facing materials and $\mathrm{CT}$ consent; and 
- $\quad$ Act with integrity and respect the independence of PGs.

3.2.4. Tenet 4: Adhering to Transparency and Accountability throughout the Clinical Trial Continuum

What it means:

Building mutually transparent and open communication with PGs on behalf of patients as part of the CT continuum and maintaining high levels of accountability.

Commitment to:

- $\quad$ Bolster trust through open dialogue and interaction with PGs and seeking their input throughout to ensure CT lifecycle and following the $\mathrm{CT}$, as required;

- Work collaboratively with PGs to better understand and address patient unmet needs, preferences and trade-offs, the burden of current treatments and disease;

- Share information with PGs and patients in a neutral, uninfluencing and objective manner, where data is presented clearly and accurately as well as in a balanced and fair context, to allow PGs to form their own independent opinion and interpretation;

- Hold ourselves to highest levels of accountability by ensuring that the independence of all stakeholders involved is maintained and by implementing clear conflict of interest and disclosure guidelines;

- $\quad$ Develop trust and confidence in the methods used;

- Transparently share the aggregate results of CTs with patients and PGs, regardless of the trial outcome, in a timely, efficient and comprehensible manner; and

- Transparently share the individual results with the patient and/or patient guardian in the case of a pediatric study, regardless of the outcome, in a timely, efficient and comprehensible manner.

3.2.5. Tenet 5: Maximizing the Potential to Collect and Utilize RWE/RWD Captured in All Clinical Trials

What it means:

Real-world evidence/real-world data (RWE/RWD) will be considered in all CTs to optimize the quality of evidence, minimize risk of bias and build upon public and stakeholder trust in research credibility and reliability.

Commitment to:

- Consider RWE/RWD in the collection of data in order to render the results more generalizable to achieve greater external validity, better support access, appropriateness of use and affordability of the therapeutic interventions being tested in CTs;

- Communicate (in lay language for good comprehension by PGs and patients), the research goals, methods, procedures, RWE/RWD collected as well as the findings resulting from the use and analysis of this data;

- Ensure that the RWE/RWD data is complete, reliable, and processed in a consistent manner. Best practices in data collection and analysis should be applied from the initiation of the trial study design and maintained throughout the CTC; and

- $\quad$ Share RWE/RWD data post CT in a timely manner to ensure the greatest impact of patients/caregivers to help with decision making.

\section{Discussion}

The International Association for Public Participation has defined five levels of engagement outlining the impact of partnership with patients in CTs, which are intrinsically conveyed in the Charter-inform, consult, involve, collaborate, and empower [2]. The Charter offers a unique and tangible framework for cancer CT stakeholders to commit to and to gauge their organizations' patient centricity in CTs. The vision integrated into the Charter is that PGs would be empowered as equal partners in CTs, completely integrated throughout the CTC, from the conception through translation.

Aligned with the Charter tenets and commitments, recommendations from the CTTI/CCTTI and other initiatives aiming at improving research co-design were to-build trust and report between researchers and co-design participants, use clear and consistent terminol- 
ogy, provide training if necessary, invest in co-design notably by allocating sufficient time and resources, empower and nurture participants to promote engagement, communicate and update all parties regularly, and report findings regardless of outcomes, to name a few $[1,4,5,11,13,17-19,28,35,44]$.

With regards to encompassing the concept of patient centricity and to enhancing research collaboration with PGs, a recent review has identified the main reported co-design activities to be focus groups, interviews, and surveys [1]. Specifically for CTs, patient involvement in developing plain-language summaries has been identified in a global industry survey as most often implemented and piloted [26]. However, the authors also reported that more organizational patient-centric initiatives are in the planning stages than are being implemented or piloted.

In terms of limitations, Heckert et al. [5] reported that challenges the most often described by investigators and partners on engagement were three-fold-(1) infrastructure to support engagement, (2) building relationships, and (3) maintaining relationships. Challenges to both building and maintaining relationships were related to having authentic, positive interactions that facilitate mutual understanding, full participation, and genuine influence on the projects. On a broader scale, patient groups are an heterogenous entity, which should be considered in assessing the challenges of their engagement in the CT continuum [49].

As reported from a survey on 25 patient-centric initiatives within pharmaceutical and biotechnology companies [26], the primary barriers to the adoption of such initiatives were to gain internal company buy-in and authority to implement them. Findings from a similar survey revealed that PGs valued their contributions to research protocol development, funding acquisition, and interpretation of study results more highly than those contributions were valued by industry and academic respondents [50]. Acknowledged by du Plessis et al. [24] following discussion from a panel of senior pharmaceutical representatives, true patient centricity requires a change in the industry's cultural mindset, an increase in public trust, clearer roles and responsibilities within pharmaceutical organizations, openness to learn from others, and a framework to measure success.

To succeed with patient engagement and perhaps to guide education and training, patient competencies identified in a recent review include an understanding of research as well as a desire to contribute to the team effort. Frisch et al. [3] further reported that several patient competencies may be learned on-the-job, and that it is not expected that all patients be able to interpret and evaluate the research, but to understand its purpose, to share their patient experience, and to show willingness to contribute to the dissemination of the study findings. Explicit in the Charter and conveyed in the stakeholder feedback received on the draft Charter is the importance of engaging patients and PGs early and regularly in the CTC, including for the collection of RWE/RWD [51]. This was reported as a key component to the success of the GO-CART patient engagement program in blood cancer as well as in research conducted in other areas, such as depression and asthma [4]. confirming findings from other initiatives [11,29,30].

Stakeholders from the CCC conferences have identified needs in several areas-1 - clearly define PG and patient roles and responsibilities; 2 - create a comprehensive communication strategy and plan; 3-build an advocacy plan; and 4-clearly define standardized metrics and measurements. Moving forward, as an aim to integrate the patient voice into the Canadian cancer CTC and using the recent CTTI recommendations on RWE/RWD [51], the next phases include the dissemination, adoption, and implementation of the Charter, the establishment of a PG training program, and the development of RWE/RWD methodologies.

Supplementary Materials: The following are available online at https: / www.mdpi.com/article/ 10.3390 / curroncol28020137/s1, Table S1: Members of the Charter working group throughout the Charter development process, Table S2: Stakeholders attending the 2019 CCC PG Pathway Model to Accessing Cancer Clinical Trials \& Real-World Evidence Methodologies Conference, Table S3: The Canadian Cancer Clinical Trials Stakeholder Charter's Glossary. 
Author Contributions: S.M., J.N., S.S., D.J., S.H. (Sabrina Hanna), S.H. (Sharareh Hosseinzadeh), V.B., P.S., S.B. and B.D.S.; Methodology, S.M., J.N., S.S., D.J., S.H. (Sabrina Hanna), S.H. (Sharareh Hosseinzadeh), V.B., P.S., S.B., N.R. and B.D.S.; Writing-original draft, N.R.; Writing-review and editing, S.M., J.N., S.S., D.J., S.H. (Sabrina Hanna), S.H. (Sharareh Hosseinzadeh), V.B., P.S., S.B. and B.D.S. All authors have read and agreed to the published version of the manuscript.

Funding: The development of the Charter received no external funding.

Institutional Review Board Statement: Not applicable.

Informed Consent Statement: Not applicable.

Acknowledgments: The authors and the WG acknowledge all stakeholders who provided feedback on the Charter various versions. The participation of Anne Marie Wright, from Elements Strategy Inc., Elle E. Doherty, from CCC, and previous members of the WG-Dawn Richards (Clinical Trials Ontario), Emanuela De Franco (Novartis), Karen Arts (N2), and Isabelle Jodoin (Novartis Canada)-in contributing in the development of the Charter is greatly appreciated. This initiative has been supported by BioCanRx-Biotherapeutics for Cancer Treatment, Boehringer Ingelheim Ltd., Canadian Partnership Against Cancer, Eli Lilly Canada, GlaxoSmithKline, Hoffman-La Roche, Innovative Medicines Canada, and Novartis Canada.

Conflicts of Interest: S.M. reports grants from Turnstone Biologics, grants from Roche Diagnostic, grants from AbCellera, grants from Immudex, grants from Miltenyi, grants from Merck, grants from Kite Pharma, grants from Novartis, grants from AstraZeneca, grants from Gilead, grants from GSK, grants from Roche Pharma, grants from Immunovaccine, grants from Zymeworks, outside the submitted work. The cancer collaborative S.H. (Sabrina Hanna) has received financial support from Hoffman-La Roche, Novartis Pharma Canada, AstraZeneca and Janssen Canada. V.B. has received fees for clinical trial management services rendered through Vantage BioTrials for the following sponsor companies: AbbVie, Laurent Pharmaceuticals, Bausch Health, McDougall Scientific, i-Med Pharma and Altasciences. V.B. has also received non-financial support for a speaking engagement for Johnson \& Johnson. V.B. has no direct ownership, equity interest in, advisory or board of director role in stated sponsor companies. Colorectal Cancer Canada (P.S., S.B., and B.D.S.) has received support from Amgen, AstraZeneca, Bayer, Boehringer Ingelheim Canada, Bristol-Myers Squibb, Canadian partnership Against Cancer, Eli Lilly Canada, GlaxoSmithKline, Hoffmann-La Roche, Innovative Medicines Canada, Janssen, Merck Frost Canada and Company, Novartis Pharma Canada, Pfizer Canada, and Pharmascience. N.R. has received consulting fees from multiple pharma companies, CROs, and medical communication firms, such as AbbVie, Treos Bio Ltd., Engage Presentations, and McDougall Scientific. The funders had no role in the development of the Charter, in the writing of the manuscript, or in the decision to publish the Charter. J.N., S.S., D.J., S.H. (Sharareh Hosseinzadeh) and P.S. declare no conflict of interest.

\section{References}

1. Slattery, P.; Saeri, A.; Bragge, P. Research co-design in health: A rapid overview of reviews. Health Res. Policy Syst. 2020, 18 , 17. [CrossRef] [PubMed]

2. $\quad$ Parry, M.; Bjørnnes, A.; Toupin-April, K.; Najam, A.; Wells, D.; Sivakumar, A.; Richards, D.; Ceroni, T.; Park, M.; Ellis, A.; et al. Patient Engagement Partnerships in Clinical Trials: Development of Patient Partner and Investigator Decision Aids. Patient 2020, 13, 745-756. [CrossRef]

3. Frisch, N.; Atherton, P.; Doyle-Waters, M.; MacLeod, M.; Mallidou, A.; Sheane, V.; Ward, J.; Woodley, J. Patient-oriented research competencies in health (PORCH) for researchers, patients, healthcare providers, and decision-makers: Results of a scoping review. Res. Involv. Engagem. 2020, 6, 4. [CrossRef] [PubMed]

4. Foster, M.; Fergusson, D.; Hawrysh, T.; Presseau, J.; Kekre, N.; Schwartz, S.; Castillo, G.; Asad, S.; Fox, G.; Atkins, H.; et al. Partnering with patients to get better outcomes with chimeric antigen receptor T-cell therapy: Towards engagement of patients in early phase trials. Res. Involv. Engagem. 2020, 6, 61. [CrossRef] [PubMed]

5. Heckert, A.; Forsythe, L.; Carman, K.; Frank, L.; Hemphill, R.; Elstad, E.; Esmail, L.; Lesch, J. Researchers, patients, and other stakeholders' perspectives on challenges to and strategies for engagement. Res. Involv. Engagem. 2020, 6, 60. [CrossRef]

6. Skovlund, P.; Nielsen, B.; Thaysen, H.; Schmidt, H.; Finset, A.; Hansen, K.; Lomborg, K. The impact of patient involvement in research: A case study of the planning, conduct and dissemination of a clinical, controlled trial. Res. Involv. Engagem. 2020, 6, 43. [CrossRef]

7. Arnstein, L.; Wadsworth, A.; Yamamoto, B.; Stephens, R.; Sehmi, K.; Jones, R.; Sargent, A.; Gegeny, T.; Woolley, K. Patient involvement in preparing health research peer-reviewed publications or results summaries: A systematic review and evidence-based recommendations. Res. Involv. Engagem. 2020, 6, 34. [CrossRef] [PubMed] 
8. Vat, L.; Warren, M.; Goold, S.; Davidge, E.; Porter, N.; Schuitmaker-Warnaar, T.; Broerse, J.; Etchegary, H. Giving patients a voice: A participatory evaluation of patient engagement in Newfoundland and Labrador Health Research. Res. Involv. Engagem. 2020, 6, 39. [CrossRef] [PubMed]

9. Hovén, E.; Eriksson, L.; Månsson D’Souza, Å.; Sörensen, J.; Hill, D.; Viklund, C.; Wettergren, L.; Lampic, C. What makes it work? Exploring experiences of patient research partners and researchers involved in a long-term co-creative research collaboration. Res. Involv. Engagem. 2020, 6, 33. [CrossRef] [PubMed]

10. Poger, J.; Mayer, V.; Duru, O.; Nauman, B.; Holderness, H.; Warren, N.; Vasquez, C.; Bibi, S.; Rasmussen-Torvik, L.; Hosseinian, Z.; et al. Network Engagement in Action: Stakeholder Engagement Activities to Enhance Patient-centeredness of Research. Med. Care 2020, 58, S66-S74. [CrossRef] [PubMed]

11. Barger, S.; Sullivan, S.; Bell-Brown, A.; Bott, B.; Ciccarella, A.; Golenski, J.; Gorman, M.; Johnson, J.; Kreizenbeck, K.; Kurttila, F.; et al. Effective stakeholder engagement: Design and implementation of a clinical trial (SWOG S1415CD) to improve cancer care. BMC Med. Res. Methodol. 2019, 19, 119. [CrossRef]

12. Michaels, D.; Lamberti, M.; Peña, Y.; Kunz, B.; Getz, K. Assessing Biopharmaceutical Company Experience with Patient-centric Initiatives. Clin. Ther. 2019, 41, 1427-1438. [CrossRef]

13. Stephens, K.; Osterhage, K.; Fiore-Gartland, B.; Lovins, T.; Keppel, G.; Kim, K. Examining the Needs of Patient Stakeholders as Research Partners in Health Data Networks for Translational Research. AMIA Jt. Summits Transl. Sci. Proc. 2019, $2019,363-369$.

14. Smith, A.; Chisolm, S.; Deal, A.; Spangler, A.; Quale, D.; Bangs, R.; Jones, J.; Gore, J. Patient-centered prioritization of bladder cancer research. Cancer 2018, 124, 3136-3144. [CrossRef]

15. Fergusson, D.; Monfaredi, Z.; Pussegoda, K.; Garritty, C.; Lyddiatt, A.; Shea, B.; Duffett, L.; Ghannad, M.; Montroy, J.; Murad, M.; et al. The prevalence of patient engagement in published trials: A systematic review. Res. Involv. Engagem. $2018,4,17$. [CrossRef] [PubMed]

16. Oldfield, B.; Harrison, M.; Genao, I.; Greene, A.; Pappas, M.; Glover, J.; Rosenthal, M. Patient, Family, and Community Advisory Councils in Health Care and Research: A Systematic Review. J. Gen. Intern. Med. 2018, 34, 1292-1303. [CrossRef] [PubMed]

17. Boaz, A.; Hanney, S.; Borst, R.; O'Shea, A.; Kok, M. How to engage stakeholders in research: Design principles to support improvement. Health Res. Policy Syst. 2018, 16, 60. [CrossRef] [PubMed]

18. Patrick-Lake, B. Patient engagement in clinical trials: The Clinical Trials Transformation Initiative's leadership from theory to practical implementation. Clin. Trials 2018, 15, 19-22. [CrossRef] [PubMed]

19. Archambault, P.; McGavin, C.; Dainty, K.; McLeod, S.; Vaillancourt, C.; Lee, J.; Perry, J.; Gauvin, F.; Boivin, A. Recommendations for patient engagement in patient-oriented emergency medicine research. Can. J. Emerg. Med. 2018, 20, 435-442. [CrossRef]

20. Haynes, S.; Rudov, L.; Nauman, E.; Hendryx, L.; Angove, R.; Carton, T. Engaging Stakeholders to Develop a Patient-centered Research Agenda: Lessons Learned From the Research Action for Health Network (REACHnet). Med. Care 2018, 56, S27. [CrossRef]

21. Warren, N.; Gaudino, J.J.; Likumahuwa-Ackman, S.; Dickerson, K.; Robbins, L.; Norman, K.; Lind, J.; D'Amato, S.; Foley, P.; Gold, R.; et al. Building Meaningful Patient Engagement in Research: Case Study From ADVANCE Clinical Data Research Network. Med. Care 2018, 56, S58-S63. [CrossRef]

22. Concannon, T.; Grant, S.; Welch, V.; Petkovic, J.; Selby, J.; Crowe, S.; Synnot, A.; Greer-Smith, R.; Mayo-Wilson, E.; Tambor, E.; et al. Practical Guidance for Involving Stakeholders in Health Research. J. Gen. Intern. Med. 2019, 34, 458-463. [CrossRef] [PubMed]

23. Kim, K.; Khodyakov, D.; Marie, K.; Taras, H.; Meeker, D.; Campos, H.; Ohno-Machado, L. Novel Stakeholder Engagement Approach for Patient-centered Outcomes Research. Med. Care 2018, 56, S41-S47. [CrossRef] [PubMed]

24. du Plessis, D.; Sake, J.; Halling, K.; Morgan, J.; Georgieva, A.; Bertelsen, N. Patient Centricity and Pharmaceutical Companies: Is It Feasible? Ther. Innov. Regul. Sci. 2017, 51, 460-467. [CrossRef] [PubMed]

25. Yeoman, G.; Furlong, P.; Seres, M.; Binder, H.; Chung, H.; Garzya, V.; Jones, R. Defining patient centricity with patients for patients and caregivers: A collaborative endeavour. BMJ Innov. 2017, 3, 76-83. [CrossRef]

26. Lamberti, M.; Awatin, J. Mapping the Landscape of Patient-centric Activities within Clinical Research. Clin. Ther. 2017, 39, 2196-2202. [CrossRef]

27. Stegemann, S.; Ternik, R.; Onder, G.; Khan, M.; van Riet-Nales, D. Defining Patient Centric Pharmaceutical Drug Product Design. AAPS J. 2016, 18, 1047-1055. [CrossRef]

28. Petersen, C.; Austin, R.; Backonja, U.; Campos, H.; Chung, A.; Hekler, E.; Hsueh, P.; Kim, K.; Pho, A.; Salmi, L.; et al. Citizen science to further precision medicine: From vision to implementation. JAMIA Open 2020, 3, 2-8. [CrossRef]

29. Forsythe, L.; Heckert, A.; Margolis, M.; Schrandt, S.; Frank, L. Methods and impact of engagement in research, from theory to practice and back again: Early findings from the Patient-Centered Outcomes Research Institute. Qual. Life Res. 2018, $27,17-31$. [CrossRef]

30. Manafo, E.; Petermann, L.; Mason-Lai, P.; Vandall-Walker, V. Patient engagement in Canada: A scoping review of the 'how' and 'what' of patient engagement in health research. Health Res. Policy Syst. 2018, 16, 5. [CrossRef]

31. Hansen, M.; Nørgaard, L.; Hallgreen, C. How and Why to Involve Patients in Drug Development: Perspectives From the Pharmaceutical Industry, Regulatory Authorities, and Patient Organizations. Ther. Innov. Regul. Sci. 2019, 7, 577-585. [CrossRef]

32. Vat, L.; Finlay, T.; Jan Schuitmaker-Warnaar, T.; Fahy, N.; Robinson, P.; Boudes, M.; Diaz, A.; Ferrer, E.; Hivert, V.; Purman, G.; et al Evaluating the "return on patient engagement initiatives" in medicines research and development: A literature review. Health Expect. 2019, 23, 5-18. [CrossRef] 
33. Domecq, J.; Prutsky, G.; Elraiyah, T.; Wang, Z.; Nabhan, M.; Shippee, N.; Brito, J.; Boehmer, K.; Hasan, R.; Firwana, B.; et al. Patient engagement in research: A systematic review. BMC Health Serv. Res. 2014, 14, 89. [CrossRef] [PubMed]

34. Concannon, T.; Fuster, M.; Saunders, T.; Patel, K.; Wong, J.; Leslie, L.; Lau, J. A systematic review of stakeholder engagement in comparative effectiveness and patient-centered outcomes research. J. Gen. Intern. Med. 2014, 29, 1692-1701. [CrossRef] [PubMed]

35. Tenaerts, P.; Madre, L.; Landray, M. A decade of the Clinical Trials Transformation Initiative: What have we accomplished? What have we learned? Clin. Trials 2018, 15, 5-12. [CrossRef] [PubMed]

36. Initiative, C.T.T. CTTI Tool—Stakeholder Identification and Analysis Tool. Available online: https://www.ctti-clinicaltrials.org/ files/recruitment-tool-2-stakeholder.pdf (accessed on 11 December 2020).

37. Clinical Trials Transformation Initiative. CTTI Recommendations: Patient Groups and Clinical Trials. Available online: https:/ / www.ctti-clinicaltrials.org/sites/www.ctti-clinicaltrials.org/files/7-revised_pgct-recommendations-2019_final.pdf (accessed on 22 November 2020).

38. Kendall, C.; Fitzgerald, M.; Kang, R.; Wong, S.; Katz, A.; Fortin, M.; Dionne, E.; Kuluski, K.; O’Brien, M.; Ploeg, J.; et al. "Still learning and evolving in our approaches": Patient and stakeholder engagement among Canadian community-based primary health care researchers. Res. Involv. Engagem. 2018, 4, 47. [CrossRef]

39. Canadian Institutes of Health Research. Strategy for Patient-Oriented Research-Patient Engagement Framework. Available online: https:/ / cihr-irsc.gc.ca/e/documents/spor_framework-en.pdf (accessed on 22 November 2020).

40. Frank, L.; Forsythe, L.; Ellis, L.; Schrandt, S.; Sheridan, S.; Gerson, J.; Konopka, K.; Daugherty, S. Conceptual and practical foundations of patient engagement in research at the patient-centered outcomes research institute. Qual. Life Res. 2015, 24, $1033-1041$. [CrossRef]

41. Brett, J.; Staniszewska, S.; Mockford, C.; Herron-Marx, S.; Hughes, J.; Tysall, C.; Suleman, R. Mapping the impact of patient and public involvement on health and social care research: A systematic review. Health Expect. 2014, 17, 637-650. [CrossRef]

42. Selva, A.; Sanabria, A.; Pequeño, S.; Zhang, Y.; Solà, I.; Pardo-Hernandez, H.; Selva, C.; Schünemann, H.; Alonso-Coello, P. Incorporating patients' views in guideline development: A systematic review of guidance documents. J. Clin. Epidemiol. 2017, 88, 102-112. [CrossRef]

43. Colorectal Cancer Canada. Learn about us. Available online: https://www.colorectalcancercanada.com/learn-about-us/ (accessed on 22 November 2020).

44. Batist, G.; Michaud, S.; Richards, D.; Servidio-Italiano, F.; Stein, B. Developing a model of a patient-group pathway to accessing cancer clinical trials in Canada. Curr. Oncol. 2018, 25, e597-e609. [CrossRef]

45. Schwaber, K.; Sutherland, J. The Scrum Guide ${ }^{\mathrm{TM}}$-The Definitive Guide to Scrum: The Rules of the Game; Creative Commons: Mountain View, CA, USA, 2017; p. 19.

46. Wrike. What Is a Sprint in Agile? Available online: https://www.wrike.com/project-management-guide/faq/what-is-a-sprintin-agile/ (accessed on 1 December 2020).

47. Canada, C.C. Canadian Cancer Clinical Trials Stakeholder Charter. Available online: https://www.colorectalcancercanada. com/app/uploads/2020/09/Canadian-Cancer-Clinical-Trials-Stakeholder-Charter-Document-2020.pdf (accessed on 22 November 2020).

48. Novartis. The Novartis Commitment to Patients and Caregivers. Available online: https://www.novartis.com/our-focus/ patients-caregivers/novartis-commitment-patients-and-caregivers (accessed on 4 November 2020).

49. Ghinea, N. Citizen Science and the Politicization of Epistemology. Am. J. Bioeth. 2019, 19, 58-60. [CrossRef] [PubMed]

50. Smith, S.; Selig, W.; Harker, M.; Roberts, J.; Hesterlee, S.; Leventhal, D.; Klein, R.; Patrick-Lake, B.; Abernethy, A. Patient Engagement Practices in Clinical Research among Patient Groups, Industry, and Academia in the United States: A Survey. PLoS ONE 2015, 10, e0140232. [CrossRef] [PubMed]

51. Clinical Trials Transformation Initiative. Use of Real-World Data to Plan Eligibility Criteria and Enhance Recruitment. Available online: https:/ / www.ctti-clinicaltrials.org/sites/www.ctti-clinicaltrials.org/files/rwd-recommendations_final.pdf (accessed on 22 November 2020). 